\title{
Research on the Reasonableness of Spatial Distribution of Emergency Shelter in County
}

\author{
Wei Zhanxiang, Hou Yunxian
}

School of Economics and Management, China Agricultural University, Beijing 100083

Keywords: emergency shelter; central area of township and town; emergency coordination

\begin{abstract}
The rapid development of urbanization in China and the spatial rationality of the layout of public service facilities in townships and towns have become the hot issues of concern to all sectors of society. This paper takes the emergency shelter in the central area of Fangshan District as an example, and studies the rationality of the spatial layout of emergency shelter on the basis of analysis of regional emergency coordination.
\end{abstract}

\section{Introduction}

Emergency shelter refers to a site of a certain scale that is used for emergency evacuation and living services and disaster prevention in response to unexpected natural disasters and accidents. It is used for evacuation during and after a disaster. New or reinforced buildings are used by public as emergency shelters to avoid disasters in the safest place ${ }^{[1]}$. As the process of urbanization is expanding and the function of life is intensified, people's awareness of public safety is significantly raised. Public emergency is urgently needed. Emergency shelters, as people's evasion of disasters, provide functional facilities for guaranteeing basic living security. Its theoretical research and practical discussion have special significance.

\section{Models and Methods}

The Proposal of the Central Committee of the Communist Party of China on Formulating the 11th Five-Year Plan for National Economic and Social Development reviewed and approved by the Fifth Plenary Session of the 16th Central Committee of the Communist Party of China further proposed to promote the healthy development of urbanization and adhere to the coordinated development of cities, towns, improve the comprehensive carrying capacity of cities and towns on the issue of emergency coordination. According to the carrying capacity of resources and environment, the development of foundations and potential, the requirements of giving play to comparative advantages, and strengthening weak links and equalizing basic public services, the gap between public services and people's living standards needs to be narrowed so as to achieve regional coordinated development pattern.

Accessibility usually refers to the level of accessibility for people reach a destination from a given location via some means ${ }^{[20]}$, and it often uses metrics such as distance, time, and cost. Accessibility is, first of all, a concept of space that reflects the level of accessibility which space entities can overcome barriers to communicate and express the density of space entities. Second, accessibility is time-sensitive, and time is the most fundamental impediment to traffic travel, so the spatial distance is usually measured in units of time. Third, accessibility has social and economic value. A higher level of accessibility is associated with quality of life, satisfaction, attractiveness, and other related things.

The statistical index method is derived from the evaluation of park accessibility, which refers to the evaluation of citizen's accessibility to the park by counting the number of shelters, area, park area ratio and per capita park area in a specific area. The higher the index value, the better the accessibility. In the evaluation of the rationality of the spatial distribution of parks, two indicators, service area ratio and population service ratio, are often selected, and the accuracy of these two indexes in the rationality evaluation of spatial distribution of urban parks has been proved ${ }^{[21]}$. From 
this approach, this article builds space accessibility evaluation index of emergency shelter, see Table 1.

Table 1 Space Accessibility Evaluation Index of Emergency Shelter

\begin{tabular}{lll}
\hline Evaluation Index & Connotation & Influence \\
\hline service area ratio & $\begin{array}{l}\text { The proportion of the total area covered by the space service capacity of emergency } \\
\text { service area of emergency shelter to the total shelter } \\
\text { area of the study area }\end{array}$
\end{tabular}

population service ratio

Service overlapping ratio

per capita park area for shelters
The proportion of the total area covered by the service area of emergency shelter to the total population of the study area

The proportion of the overlapping portion of the service area of each emergency shelter and other shelters to the sum of the service areas of various emergency shelters service capability provided by emergency shelters to evacuees
Reflect the emergency shelter space layout redundancy and mutual reinforcement
Within the coverage area of the site, the emergency shelter area accessible and utilized by per capita in the study area
Measure the level of service provided by residents in the places of refuge actually enjoyed within a certain distance of travel

The statistical indicators mainly cover the determination of the population of emergency shelter area, service area and population in the service area. These indexes determine the coverage radius of emergency shelters by GIS spatial analysis, and then determine the population within the coverage area through population density analysis. The calculation of the service overlap area is based on the sum of the areas of various shelters measured by GIS minus the area of the sheltered refuge.

\section{Empirical Study}

Based on the synergetic theory, this paper re-plans and integrates the layout of emergency shelters in Fangshan District, forms an efficient and orderly "integrated" cooperation mode in adjacent areas with common features, and forms a coordinated and unified disaster coordination system, through which the overall emergency reaction capacity and evacuation efficiency will be enhanced.

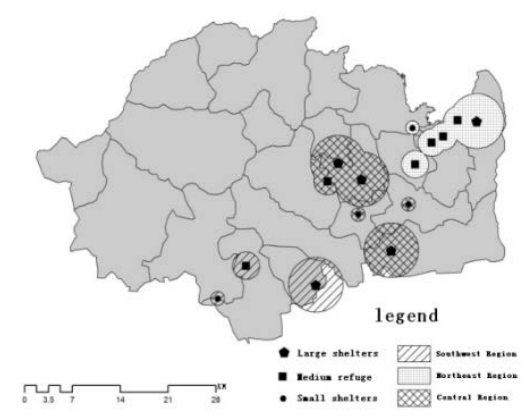

Figure 1 The existing emergency shelter collaborative regional service area 
In order to simplify the analysis, we first use the ArcGIS10.2 software platform to generate a regular grid of the research area, and then superimpose it with the population density distribution diagram to obtain the population distribution on the grid, and then modularize the models and methods to form the technical route mentioned in this article.

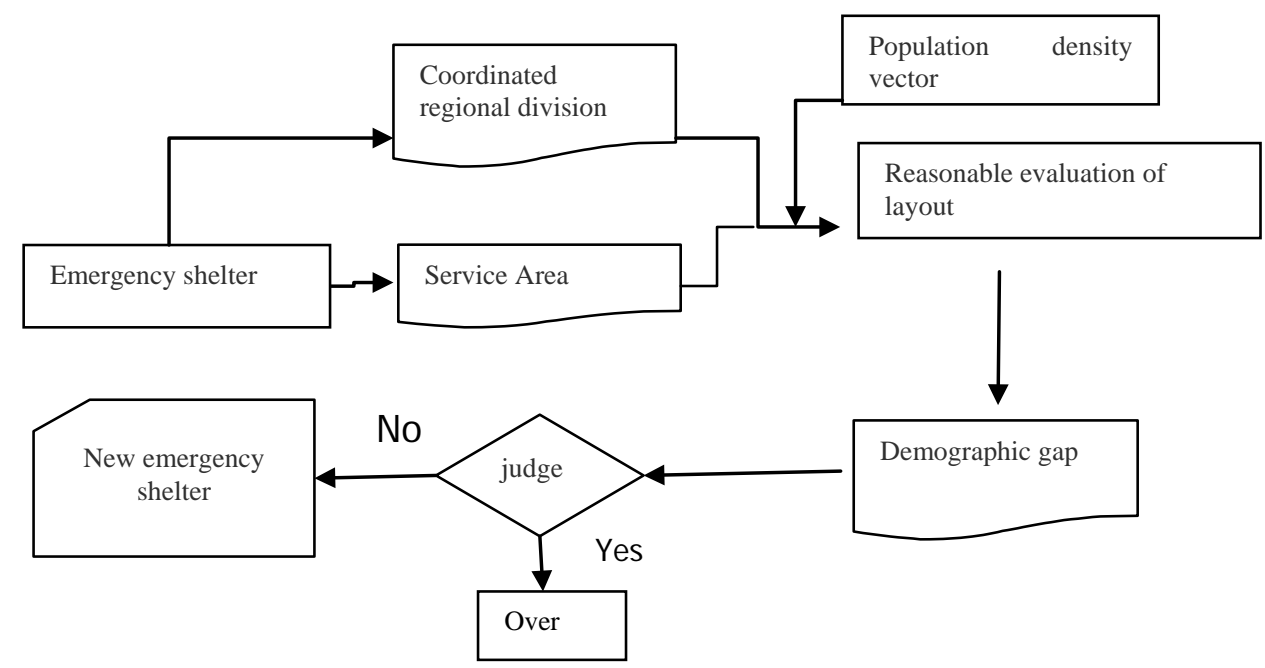

Figure 2 Technical Route

The evaluation of the spatial layout of emergency shelters mainly includes the overall evaluation of the coordination area and the specific analysis of each area. According to the division of the coordinated area and the people-oriented principle, we evaluate the overall service level of the emergency shelter from the perspective of the coordinated regional division, then evaluate the allocation shortage of the original emergency shelter, and then consider the population distribution, population concentration, risk sources, buildings and other factors, the new emergency shelter will be constructed based on the availability of land. The new emergency shelters will be located in a safe area with the highest population density and far from the risk source and minimum number of addresses will be established. People-oriented principle and the stay-to-the-nearest rule for the optimization of spatial layout guidelines are followed to achieve the system optimization of construction cost and social benefits.

Table 2 Service index statistics of emergency shelter in coordination area

\begin{tabular}{|c|c|c|c|c|c|c|c|c|c|}
\hline District & $\begin{array}{l}\text { Regional } \\
\text { total area } \\
\mathbf{A}\left(\mathbf{k ~ m}^{2}\right)\end{array}$ & $\begin{array}{l}\text { Regional } \\
\text { total refugee } \\
\text { population } \\
\mathbf{P}_{\mathrm{s}}(\mathbf{1 0 , 0 0 0 )}\end{array}$ & $\begin{array}{l}\text { Total area } \\
\text { of all } \\
\text { shelters } \\
\sum \mathbf{S A}\left(\mathbf{k m}^{2}\right)\end{array}$ & $\begin{array}{l}\text { Total } \\
\text { area of } \\
\text { each } \\
\text { shelter } \\
\sum \text { SO } \\
\text { (km2) }\end{array}$ & $\begin{array}{l}\text { Total } \\
\text { refugee } \\
\text { population } \\
\text { of all } \\
\text { shelters } \\
\sum \text { SP } \\
(\mathbf{1 0 , 0 0 0 )}\end{array}$ & $\begin{array}{cc}\text { Ratio of } \\
\text { service } \\
\text { area } \\
(\%)\end{array}$ & $\begin{array}{l}\text { Ratio of } \\
\text { service } \\
\text { population } \\
\text { P (\%) }\end{array}$ & $\begin{array}{l}\text { Service } \\
\text { overlap rate } \\
\mathbf{O}(\%)\end{array}$ & $\begin{array}{l}\text { Per capita } \\
\text { refuge area } \\
\text { AP }\end{array}$ \\
\hline $\begin{array}{l}\text { Northeastern } \\
\text { Part }\end{array}$ & 289.71 & 18.66 & 86.00 & 104.00 & 6.26 & 35.79 & 33.54 & 17.06 & 4.61 \\
\hline Middle Part & 460.67 & 21.47 & 142.00 & 170.00 & 8.13 & 36.83 & 37.88 & 16.30 & 6.61 \\
\hline $\begin{array}{l}\text { Southwestern } \\
\text { Part }\end{array}$ & 298.70 & 8.25 & 66.00 & 66.00 & 3.13 & 22.09 & 37.91 & 0.00 & 8.00 \\
\hline
\end{tabular}

Through the analysis of Table 2, we could find that the overall ratio of service area of emergency shelters in Fangshan District is relatively low at 28.02\%, with a respective ratio of $35.79 \%$ in the northeast, $36.83 \%$ in the middle and $22.09 \%$ in the southwest. According to the overall analysis, all emergency shelters could provide service for $36.22 \%$ of refugees in the maximum service radius, with service ratio of $33.54 \%$ in the northeast, $37.88 \%$ in the middle and $37.91 \%$ in the southwest respectively, indicating that the distribution of emergency shelters matches with population density distribution. 
(1) Population density of these areas is over 700 per square meter so that the establishment of new emergency shelters still fails to meet the needs of shelter. In the meantime, the land resources in these areas are relatively short, lacking conditions to build large emergency shelters. So the construction of multi-level shelter must be taken into consideration which should focus on constructing emergency shelter, making up for the lack of construction of large and medium-sized shelters in order to effectively solve the residents' safety issues.

(2) The new emergency shelter in northern mountainous area can basically meet the needs of local residents, but the spatial distribution is still uneven, which can not perfectly match with the population distribution characteristics of the region. Therefore, it is suggested that Da'an Mountain, Shijiaying, Nanjiao and other towns exceed other northern mountains in both quantity and size of new emergency shelter.

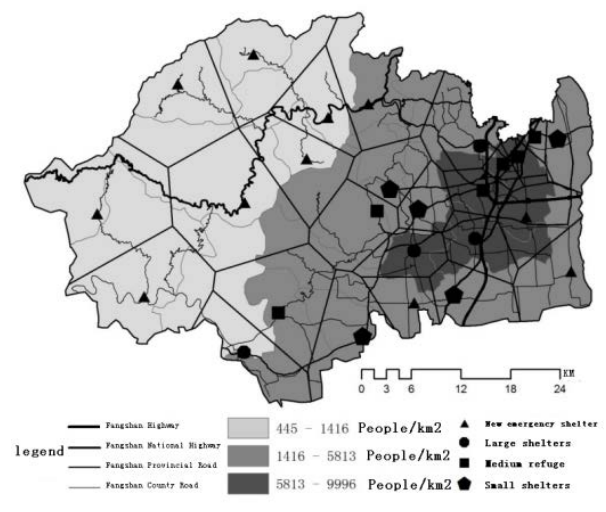

Figure 3 The distribution of new emergency shelters in Fangshan District

\section{Conclusion and Discussion}

Based on the reachability analysis, the population gap in different regions is calculated, and the optimization plan for the allocation of space for emergency shelters in Fangshan District is obtained. The main conclusions are as follows:

(1) The overall layout of Fangshan District is relatively reasonable. The emergency shelters can meet the needs of population evacuation. The scope of service space for evacuation shelters in each area is quite different and the number of service population is quite different. Among the three areas, the layout of the southwest region is more reasonable than other regions.

(2) Following the principle of people-oriented and immediate arrangement, the site selection, scale design and service scope of emergency shelters are optimized according to the population density of different administrative regions so that residents can enjoy emergency public services nearby.

\section{Acknowledgements}

Fund Project: National Social Science Fund (14BGL062); National "Twelve Five" science and technology support program topics (2014BAL07B04, 2014BAL07B05)

\section{References}

[1] Su Youpo. Urban Disaster Shelter and Evacuation Sites[M]. China Science and Technology Press,2006.

[2] Yi W, özdamar L. A dynamic logistics coordination model for evacuation and support in disaster response activities[J]. European Journal of Operational Research. 2007, 179(3): 1177-1193.

[3] Li Gang, Ma Donghui, Su Jingyu, etc. Study of Urban Earthquake Emergency Shelters Planning[J]. Journal of Beijing University of Technology. 2006, 32(10): 901-906. 
[4] Ni Guanqun, Xu Yanfeng, Xu Jiuping. The Location Models and Algorithms for Emergency Shelter with Traffic Capacity Constraint[J]. Chinese Management Science. 2015, 23(1): 82-89.

[5] Chen Zhifen, Gu Linsheng, Chen Jin, etc. Study on the Layout of Emergency Shelters in Cities (I) - Analytic Hierarchy[J]. Journal of Natural Disasters. 2010, 19(3): 151-155. 